\title{
Every Child Counts
}

Aarti Kumar

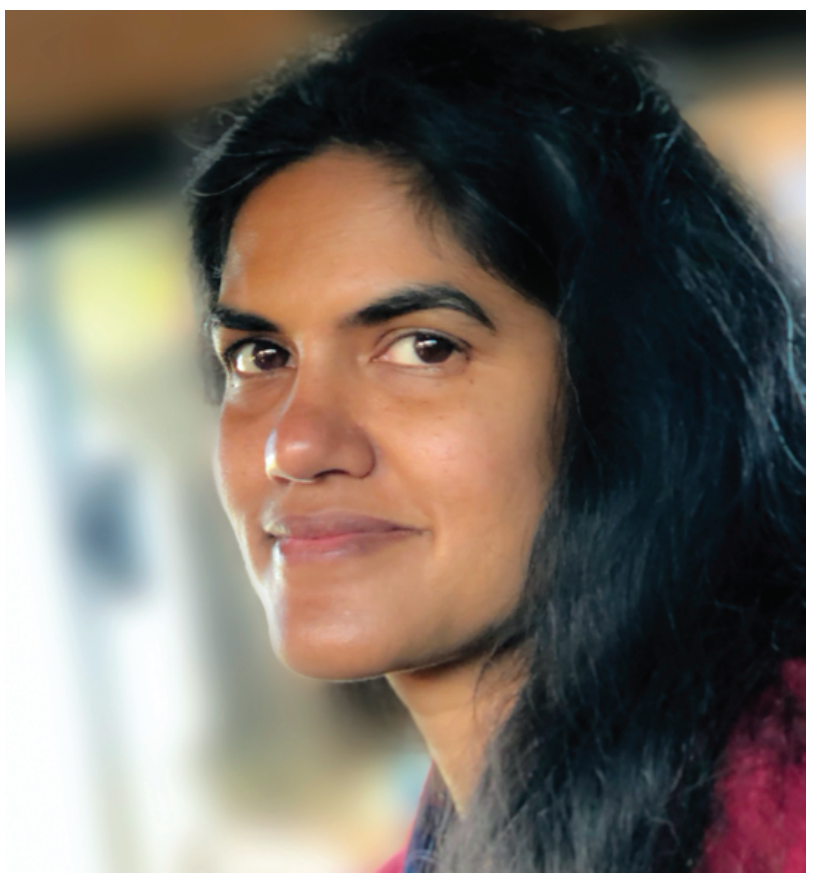

An accomplished child, Aarti Kumar grew up in Bhopal, where her father worked for Union Carbide when the 1984 gas leak happened. Her search for meaning began in the university, and continued though a corporate career, further studies, and a research position. She found her path when she met her husband, Vishwajeet. Aarti and her husband work in rural Uttar Pradesh towards eliminating preventable deaths in mothers and newborn children by integrating cutting-edge science with deep empathy. 


\section{Growing Up}

The difference lies in whether you approach the world with holeness or wholeness, says Aarti Kumar while reminiscing on her life from her home in Lucknow.

Aarti grew up in a loving and protective environment in the laid-back city of Bhopal. She had the privilege of growing up in a trusting and close-knit neighborhood where children lived and played with gay abandon, and could be found in each other's homes even late in the night without the parents fretting about it. Her idea of family, therefore, was never restricted to the four walls of what people call home. She grew up with the concept of family as boundless and ever expanding.

Being the first daughter in a joint-family household after two elder male cousins and her brother Raj, elder to her by two years, Aarti was much loved and pampered. Your granddaughter will turn out to be brilliant. You will know as she will be able to hold your gaze even when you first meet her was the prophecy of the astrologer to her grandfather when she was born. While not superstitious, her grandfather, who was in the Indian administrative services, was pleasantly surprised when he came to see her in the hospital ward and she held his gaze for the longest time. It was then that Aarti's father decided that he would commit himself to grooming and nurturing his daughter's mind. The father-daughter bond was instinctive. Even as a baby, she would stay awake until her father came home from work, often late in the night.

The year 1984 was fateful. Her grandfather, who was an authoritative guardian of the family, passed away in May. Then, the most tragic night for the city of Bhopal happened on December 2. The world's worst-ever industrial disaster 
- the Union Carbide gas leak killed more than 10,000 people. Their home was located far away from the plant and while they did not suffer any ill-health effects, the tragedy still had a huge impact. Aarti was 6-years old and fast asleep with her grandmother with windows shut on that cold winter night. Her father was a senior manager with Union Carbide at the time, and the event threw the family's future into uncertainty.

Aarti's father took up the responsibility for the rehabilitation of the widows of the factory workers on behalf of Union Carbide. For the next 8 years, he led this welfare organization that empowered widows from the tragedy with skills to stitch attractive leather items and marketed their products globally. These formative years instilled in her a deep sense of public service, though she did not realize it at the time. Life also took a slower pace and this gave her father the opportunity to spend more time coaching his children, which he consciously and happily chose over more lucrative opportunities for career progression that involved relocating to bigger cities like Mumbai.

During her schooling years, Aarti was always looked upon with awe. I was this role model everywhere, be it at school or with family or friends. She faced this constant inner pressure of expectation, of having to live up to an ideal that others had already set for her. It was an ideal of someone who could do no wrong, was absolutely clear about her life goals, and wellahead on the road to achieving them. In reality though, I was clueless. She secretly harboured thoughts of being a full-time mother but posed as though she wanted to be the CEO of a multinational company. She ticked all the boxes: learn French - check; complete a computer science diploma from the National Institute of Information Technology (NIIT) in the eighth grade (her other course mates were at least 
graduates) - check; National Talent Search scholarship check; score more than $90 \%$ marks in the twelfth grade check; Indian Institute of Technology - check. Done. Now what? No clue. I just went about diligently following my father's guidance.

\section{University Life}

Aarti's father saw the advertisement for the Singapore Airlines - Neptune Orient Lines (SIA-NOL) scholarship. The scholarship was still in its nascent stages, Aarti's being the fourth intake. She was the first one to be awarded the scholarship from Madhya Pradesh, along with her dear friend from school, Shefali Nagpal, who also made it. When Aarti landed in Singapore, she realized that prior to her batch, there were hardly any girls who received the scholarship at Nanyang Technological University (NTU). The previous three batches only had six girls among about sixty scholarship holders. My batch added the much-needed diversity with some eight girls joining the program. For Aarti and many in her batch, it was also a sudden transition to co-education, awkward, at best.

The experience of getting the scholarship was a journey into the unknown for her. Her parents were overjoyed but had a deep sense of loss too. It was akin to marrying off their daughter as she would be gone for 10 years, 4 years for studies and 6 years to fulfill the scholarship bond of working in Singapore. But Aarti's mind was screaming, Yay, I will finally be on my own and financially independent too! I definitely went with a sense of adventure. It was all that was on my mind. The first dose of this adventure came in the form of her landing in her room in NTU, only to be told by her senior that the adjacent room belonged to a male student and that they would be toilet-mates sharing the common toilet between the 


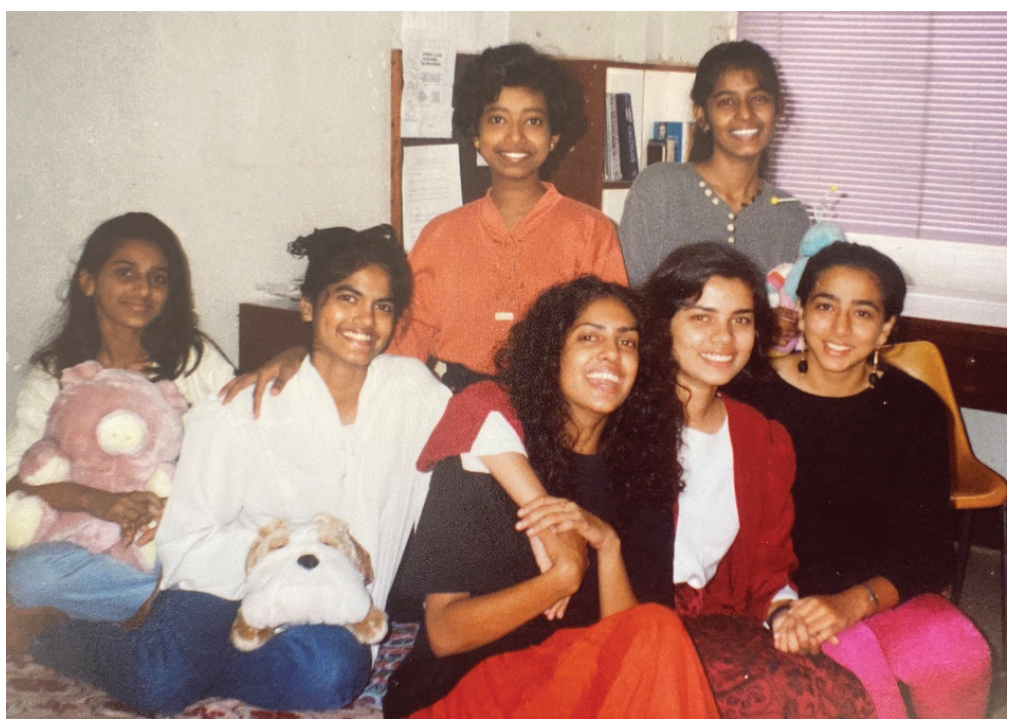

Aarti (second from left) with the girls in her batch, Singapore, 1996

two rooms. A shocked Aarti was already perplexed about explaining unisex hostels to her parents. A common toilet with a guy next door was more than the adventure she had signed up for! Thankfully, it turned out to be a joke.

Aarti has vivid memories of the "orientation" at NTU. Her seniors told her that the purpose of the orientation was to acclimatize the freshly-landed students into their home for the next 4 years, and to make sure they did not get homesick. Typically, such orientations were supervised by the immediatesenior batch. In practice, the orientation was a euphemism for skits and entertainment that the first-year students had to perform every evening during the first 1 or 2 weeks for their seniors, until wee hours running well past 2 am. This resulted in students landing up in morning classes the next day half asleep or not at all. The chilled lecture rooms in NTU and unfamiliar accent of lecturers too had a soporific effect...zzzzzz. Aarti jokingly recalls that after a few iterations of this, she 
decided to skip class altogether and sleep in the comfort of her room. She soon lost the thread of lectures and ended up skipping class for pretty much the entire first year.

If school years were like a race to check all the boxes and pick up trophies, university was exactly the opposite. Somewhat tired of running like a racehorse without a sense of purpose, university was a big pause in her life. She recalls a conversation with a friend, Amey Laud, who asked her lots of "why" questions that precipitated a traumatic realization that she was completely alienated from her real self and leading someone else's life. She gave up the chase, spending her university years mostly experimenting with who she really was. She vividly recalls her apprehensions while sharing her average first-year grades with her parents. A departure from excellence was not something I was proud of, but their acceptance liberated me from the pressure of expectation.

Shrutilaya (vocal music), baaja parties (instrumental music) and sabo's (celebrating birthdays with cake and sambar and ketchup and egg being smeared on one's face rather than being eaten), along with adventures such as cycling to a cemetery late at nights make up the remainder of her memories at NTU. Fitness and drama were new indulgences. She was well-known for her singing. I would sing any and everywhere - while waiting in line in the canteen, in the bathroom (of course), even in the MRT, Singapore's Mass Rapid Transit trains.

She feels that studying in Singapore on scholarship was life changing. I am not even sure of the kind of person I would have been had I stayed back in India. NTU allowed me the space to experiment with myself, my personality, and my life choices in a way where there were no expectations from anyone. There was no judgment. It was an entry point into the lab of my life. 


\section{Ikigai - Maternal \& Neonatal Health}

Upon graduation, Aarti took up a consulting job in an e-commerce company. I thought consulting would give me the diverse exposure to discover what I would like to do for the rest of my life. Scient was a new-age company with its fluorescentpainted office on the fortieth floor of Suntec City. I was among the best paid of all my batchmates and spent my first month training in San Francisco. Life was great and intellectually stimulating. However, as luck would have it, within 6 months of her joining in 2000, the dot-com bubble burst. As the Vice President announced the news of retrenchment to a roomful of people including her, she found herself smiling in amusement. I had never imagined that this too could happen! She recalls that at the end of the meeting, the VP actually walked up to thank her, perhaps, because I was the only one smiling in the room.

The initial amusement soon turned into gripping uncertainty. She did not share the news with her parents to spare them the anxiety. You promised your dad a car. You better buy him one soon, her grandmother said on the phone. But Aarti still did not have the heart to tell them. Fortunately, the company still had a large project in Singapore, and offered Aarti a temporary position with double her original salary. Phew! I can still afford the car. Eventually, in about 5 months, she did find a good position at Hewlett-Packard (HP), albeit with a sharp pay cut. I took a month-long break, went to India, got my dad a Maruti Zen, and finally told them that I had lost my job but found a new one. Though this uncertainty was hard, it fueled her quest to find meaning in her life.

My job at HP was generally mundane, although I enjoyed working with a great team. Then, Aarti started getting severe backaches. In hindsight, they may have been a sign of depression borne out of taking all the load myself, and not really having 
anyone to confide in. Being in deplorable health at the young age of 22 was unacceptable to her. She was determined to fight her way back to fitness, which she did. Shri Krishnan Ramakrishnan, the father of a good friend, came as a mentor at this difficult time. He chided her for her lack of fitness, and pushed her hard to regain her health. Fitness became a way of life and still serves her to this day. She remains ever grateful for his not-so-gentle nudges. He shared his life lessons, egging her on to take charge of her life.

Along the way, a process of spiritual unfolding began. One day, she learnt about a talk on "The wisdom of the Vedas" by a renunciate swami, who was an alumnus of the Indian Institute of Technology (IIT). Until then, she had associated religion with superstition, but this guy was an IITian, so surely should make some sense. She ended up attending, and it became a turning point in her life. His opening line, The Vedas claim that no one in this world is an atheist, caused her to smirk. But his subsequent explanation is firmly etched in her mind. He had said, The reason we constantly run around looking for happiness in every fleeting experience, be it a job or a gift or a celebration, is that what we truly crave is a union with the ultimate reservoir of all bliss, and that reservoir is God. Every being is seeking this source from deep within, and so, verily, no one is an atheist. She finally knew what she had been seeking all along. She began reading the Bhagavad Gita and finished it in two days. It made a lot of sense to her. She quotes from the Gita, 'swa-dharme nidhanam śhreyah para-dharmo bhayāvahah' (chapter 3, verse 35). It is better to die in pursuit of your 'swadharma', than pursue another's path, which is dangerous. 'Swadharma' is one's unique duty towards upholding universal wellbeing that is in harmony with one's own nature, aptitude and competencies, and in accordance with the needs of the time, place, and context. 
Aarti embarked on a quest to discover her swadharma. Taking the printer to every home wasn't exactly her idea of purpose, and she began to experience a burning desire to make a real impact in peoples' lives. I even said this to my manager in HP during one of my appraisals, and she had no clue how to respond, she chuckles. Aarti toyed with the idea of pursuing medicine in the US, much to her parents' chagrin, who felt it was about time she settled down. That is such an Indian thing that most women end up having to face. But the colossal academic fees and the hanging noose of the scholarship bond in Singapore gave her cold feet. She decided to take one step at a time and enrolled into a master's program in Bioinformatics at NTU, which she saw as a middle ground between pursuing medicine and putting her computer engineering degree to work. The idea was to toe her way into academia and make a difference to peoples' lives that way. She finally got back the fire in her belly and made up for the guilt of average grades during her bachelor's with a stellar performance in her master's.

After 4 years at HP, she took the plunge into accepting a research position at NTU despite a sizable pay cut. By this time, most well-wishers felt that I had completely lost it, but for the first time ever in my life, I was taking a decision with full conviction, and was finally on the path to finding myself. Going back to India was still a far-fetched idea. Though she always wanted to contribute to my beloved motherland, she felt it would be wiser to complete her Ph.D. and then return in a position of strength to be able to make a significant contribution. My most fervent and only prayer to God was to thank Him for blessing me with a good mind and boundless gifts, and to lead me to the path of my swadharma, so I could channelize my gifts for the world. I was in a state of complete surrender. 
My prayers were magically answered. She met her husband Vishwajeet Kumar, an alumnus from Johns Hopkins University, on the matrimonial website shaadi.com, where he had shared about his scientific and community work in rural Uttar Pradesh (UP) in India, pursuing his life's purpose of ending preventable newborn deaths. There were several eerie coincidences, including both of them sharing the same birthday. There was a deep alignment in every sense. My understanding of Karma yoga was largely theoretical, but he was living it every moment, although he had never read the Gita. Aarti married Vishwajeet and moved to India in late 2006, after just 6 months of the "knowing each other" phase. It was just the perfect match - a marriage of mind, soul, and purpose. Vishwajeet and Aarti are based in Lucknow, the capital of UP, and Shivgarh, their rural basecamp 75 kilometers from the state capital in Raebareli district. Despite skepticism from well-wishers on the difficulty of adjusting back to India after a decade in Singapore, Aarti found it to be a seamless transition. This is largely due to the immense love that I have received, both at home in Lucknow and Shivgarh, and from the scientific and development community that we collaborate with across the globe.

Aarti says, India accounts for a quarter of the global burden of preventable newborn and maternal deaths, and UP accounts for a quarter of India's burden, making it the global epicenter of newborn deaths. The state loses more than 200,000 newborn lives each year. Aarti's husband Vishwajeet calls this the "silent tsunami", as an equivalent number of lives were lost globally during the devastating tsunami of 2004. But these newborn deaths go unnoticed and unsung, year after year. If we can solve this challenge in UP, we can solve it in most high-mortality settings in the world, he says. An intervention that Vishwajeet and his team developed in 2003 and evaluated in Shivgarh in rural UP led to a dramatic 54\% reduction in newborn deaths. It is one of the seminal studies that has 


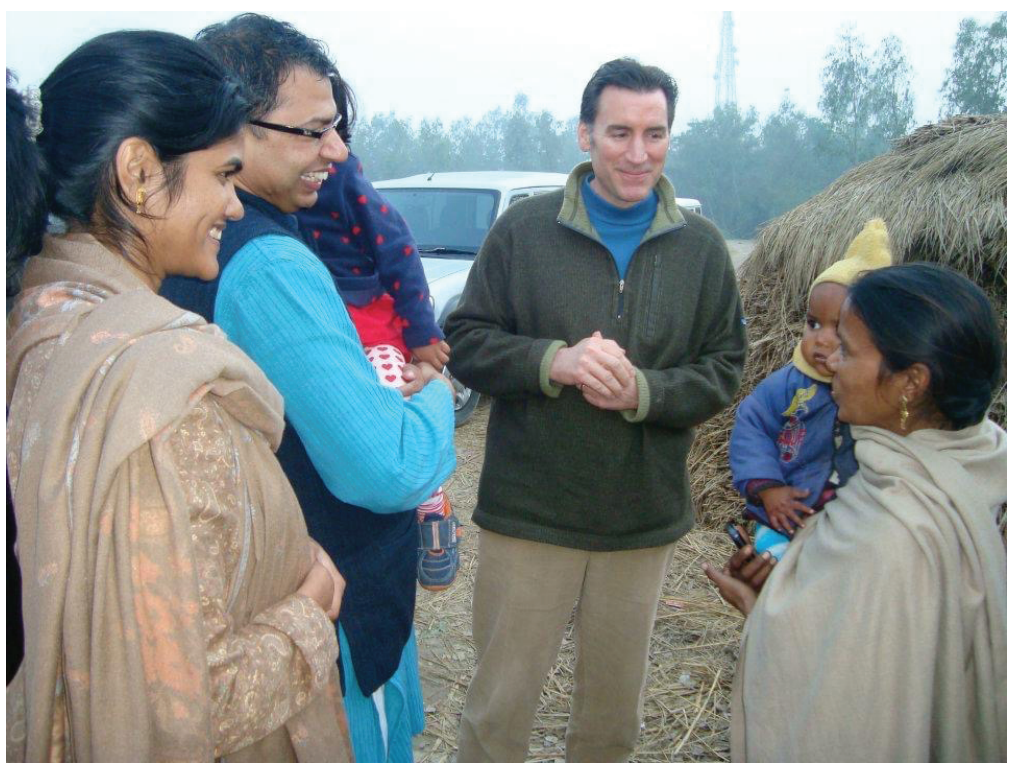

Aarti and Vishwajeet with Professor Gary Darmstadt of Stanford University during an interaction with a mother, Shivgarh, 2011

informed the World Health Organization's global policy on community health workers for maternal and newborn care. But as Vishwajeet and Aarti have learnt since 2003, designing a promising innovation is the easier part of the challenge, but scaling it at high fidelity to impact lives at scale is a challenge that is several higher orders of magnitude.

They set up the Community Empowerment Lab (CEL), an organization with a vision to end preventable deaths among mothers and newborns by integrating cutting-edge science with deep empathy. There is a large community of scientists and innovators across the globe working to address these challenges. Many believe that technology will provide the answers. We agree that technology is an important enabler. But fundamentally, the challenges that we confront are human challenges, and can only be addressed if we design solutions that elevate the human being - human potential, motivation, 
and spirit. There are many parts of the complex puzzle that they have set out to solve, and it involves deep collaboration with scientific teams across the world, close partnership with the government, and above all, a respectful partnership with the people and communities whose lives they aim to impact. It's important to see disadvantaged communities as a critical part of the solution, and not as the problem. Our philosophy is, 'Every human is a greater possibility'. Be it the illiterate mother, an unsupportive husband, or a poorly-skilled health worker, our first step is to believe in and visualize the latent potential in people, the better self that is hidden within, which needs to be kindled for it to manifest itself. This empathic relationship with the community is foundational to their design of innovations and systems solutions.

Over the years, they have developed and refined a multi-step approach to designing systems solutions to the different aspects of the puzzle, such as improving birth practices, care of premature and low-birth-weight infants, management of newborn infections, etc. They call their first step "Deep Listening", where their team spends a considerable amount of time, sometimes months, of immersive observations, conversations and experiential learning to get into the skin of the problem and understand the people and the context. They then work with all key stakeholders involved through a series of brainstorming sessions and workshops to co-design solutions that generate value for every stakeholder. Over the years, we have learnt to appreciate that not all stakeholders may be as invested in saving the life of the mother and newborn as us, nor do we expect them to be. The mother and the family are even more invested in their child than us, but a nurse, for example, may be far less. We just need to understand their respective needs and motivations, and design win-win solutions where serving the interests of the newborn and mother is aligned to serve their self-interest as well. They use rigorous 
scientific methods such as randomized controlled trials to evaluate the impact of these innovations. The most promising innovations can then be scaled, usually through the health system, through an iterative process to ensure integration, adoption, and quality.

They have applied this methodology to scale up Kangaroo Care, the most promising innovation to improve survival and brain development amongst preterm and low-birth-weight infants, across UP, in partnership with the state government. Kangaroo Care involves close skin-to-skin contact between the mother and baby along with exclusive breastfeeding and supportive care. It has forty years of irrefutable scientific evidence, and despite policy backing, has proven stubbornly challenging to scale across the world. But Aarti and Vishwajeet believe they may have cracked the code. Kangaroo Care is all about the mother manifesting her inner power to nurture and nourish her infant. She needs to feel comfortable in her skin, respected, and empowered to be able to provide life-saving

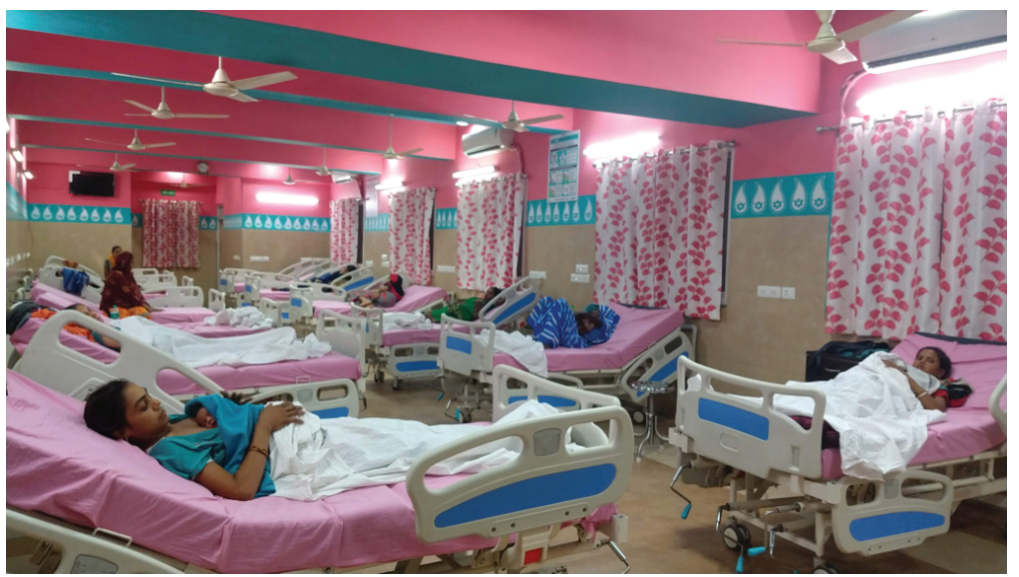

A Kangaroo Care Lounge in Badaun district, Uttar Pradesh, 2019 
Kangaroo Care to her infant. They focused on this need of the mother as a fundamental part of the solution and co-designed the Kangaroo Care Lounge with mothers and health system stakeholders. It was identified as a national best practice in India, and the UP government has scaled up 174 such lounges that provide free-of-cost services across public health facilities in UP. Their efforts are currently focused on strengthening the quality of care in these lounges, and also passing on best practices to support other global teams in scaling up Kangaroo Care in their respective geographies. Nurses are the mainstay of care in public health facilities. Our quality improvement innovations, including a 'Kangaroo Mother Care (KMC) app', are focused on empowering them, nurturing their self-esteem and addressing their unmet need of professional respect and recognition.

Aarti and Vishwajeet, along with their organization CEL, have received several awards and recognition for their work. Their work was recently featured in Melinda Gates' maiden book, The Moment of Lift: How Empowering Women Changes the World. We have embarked on a long journey, and it's beautiful how the path leads you from superficial simplicity to confused complexity, and towards profound simplicity, as you go deeper and deeper in your pursuit. Not only have we moved closer to unlocking transformative solutions, we have evolved both intellectually and spiritually, and most of all, have been blessed with deep and enriching relationships across the world. In March 2020, on International Women's Day, Aarti took over the leadership of CEL from Vishwajeet, and serves as its CEO.

\section{Aarti - The Person}

Our professional and personal lives are seamlessly integrated. There are no boundaries whatsoever. Their elder daughter, 
Shaambhavi, at 11 years, has attended several global meetings with them. Our community is very open and welcoming. All our professional colleagues and scientific collaborators the world over know her and even miss having her when she doesn't join us because of school. Their younger daughter, Akshara, at 4 years, is a fountain spring of curiosity and accompanies Aarti during her field visits to meet mothers and babies. Their parenting style is inspired by Kahlil Gibran's "On Children" from his opus, "The Prophet". It is about leading their life by example, with courage, conviction, and a sense of purpose. We don't really 'teach' our girls anything because we don't believe that children learn as much by following instructions. They learn by keenly observing our own words, actions, and consequences as parents. So, the real deal is about raising ourselves, not our children. There is actually far more to learn from children than to teach them. No wonder then, that Shaambhavi started a social business at the age of 7 along with her closest friends, truly remarkable children hailing from the slums in Lucknow, who diligently attend school while also earning wages to support their families. Akshara is a deep thinker and a very sensitive child who deeply cares for everyone around her including her animal friends. Animal babies die more than human babies because we take them away from their mums, she spontaneously reflected mulling over the loss of their beloved dog, Mufasa, and a life-threatening episode of illness in their young puppy in March 2021. Aarti says, I really wish her wisdom was shared by healthcare providers who separate newborns from their mothers at birth, and keep sick newborns away from their mothers in sanitized wards. Many lives could be saved!

Music is something that is very dear to Aarti. She is deeply influenced by her Guru, Mrs. Kalyani Puranik, who has taught her Hindustani Classical vocal music. She has taught me that it's not about the technicalities, but how much love and devotion you are able to pour into every note that you sing. You see - the Sanskrit word for note is 'sur', which is also a word that refers to God, so music is all about seeing God in every note. If I have ever 
felt even a fleeting sense of complete oneness with the divine, it has been while singing with her, tears rolling down my cheeks.

A value that she holds close to her heart is "respect", neither looking up nor down at people. "Being 'thankful for what she has", "being truthful to herself", and "having the courage to stay true" are values dear to her. She feels lucky that her life has crisscrossed paths with so many amazing people who have had a deep influence on her. There is so much to learn and so many inspiring people. I have had the good fortune of being closely associated, supported, and mentored by many wise and accomplished people. She also feels fortunate that despite their unconventional life choices, both hers and Vishwajeet's side of the family have truly supported and encouraged them, despite all the anxieties of being on a continuous roller-coaster ride. Blessings are the only true wealth that we can earn in this lifetime. I am so deeply thankful to God that I can't even count mine.

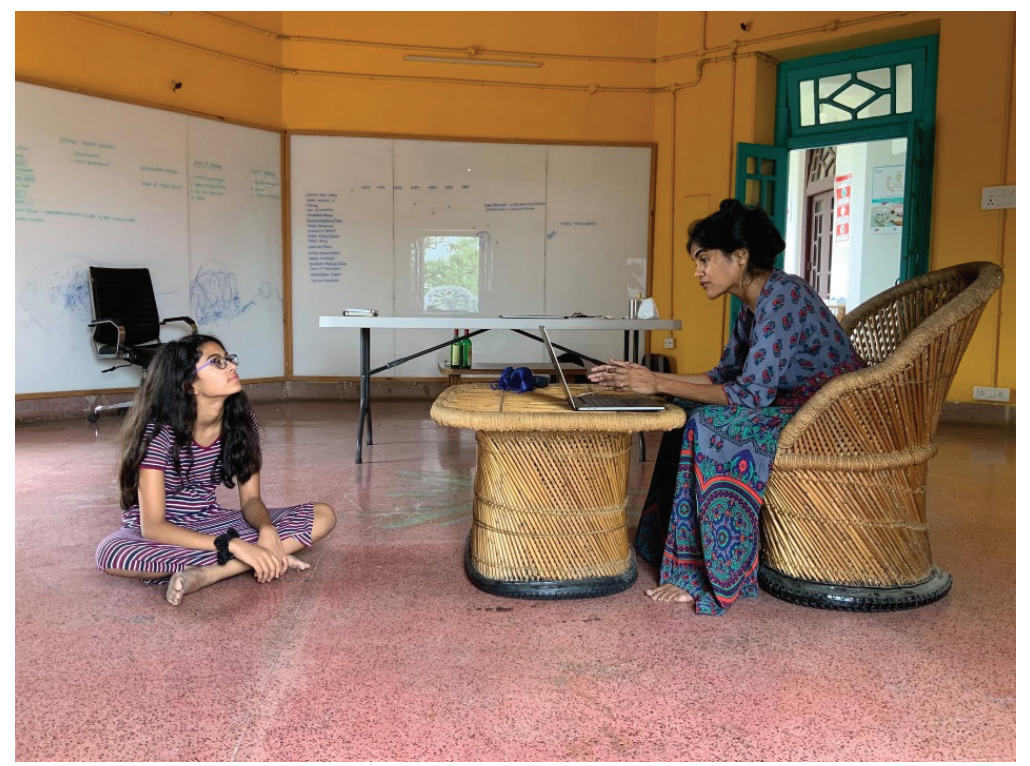

Shaambhavi listens to her mother address school students on video, Shivgarh, 2020 
When asked about her greatest challenge, Aarti points to herself. You are the greatest limit to what you can achieve. I am a work in progress. My life has been an exercise in dumping my preconceived beliefs and expanding my consciousness. It may take several more lifetimes, but the eventual goal is to experience absolute oneness with the universe. She continuously strives to evolve as a human being. What is an advice that she would give to her younger self? Nothing. Everything happens at the right moment when you are prepared for it. The only struggle is whether you are ready for the challenge.

According to her, the most important skill is the ability to transform setbacks into opportunities. She describes "holeness" as the feeling that you are a victim or that you need something to fill the bottomless hole within. You look out for things that can help you fill that hole and become a burden on the planet. Victimhood takes you nowhere, but only plunges you into a deeper and deeper abyss. In contrast, when you are operating from a sense of 'wholeness', you feel thankful for what you have and feel like sharing it. You feel complete. You do not judge people. For Aarti, this feeling of wholeness is what defines happiness.

Her goals are the same as that of their lab, to eliminate preventable infant mortality, provide respectful care for mothers, and to ensure that babies get the right environment to develop. She wants to become a better human being - a better spouse, a better parent, a better leader.

Her advice to the person reading her story is, It is the questions that are important, not the answers. Ask yourself the hard questions. Don't shy away from them because life is the only school where you take the test first and the lessons come later. 